\title{
Association of religiosity and spirituality with quality of life in patients with cardiovascular disease: a systematic review
}

\author{
Hawa O. Abu ${ }^{1}$ - Christine Ulbricht ${ }^{1}$ - Eric Ding ${ }^{1}$ - Jeroan J. Allison ${ }^{1}$ - Elena Salmoirago-Blotcher ${ }^{2,3,4}$. \\ Robert J. Goldberg ${ }^{1} \cdot$ Catarina I. Kiefe ${ }^{1}$
}

Accepted: 5 June 2018 / Published online: 11 June 2018

(c) The Author(s) 2018

\begin{abstract}
Purpose This review systematically identified and critically appraised the available literature that has examined the association between religiosity and/or spirituality (R/S) and quality of life (QOL) in patients with cardiovascular disease (CVD). Methods We searched several electronic online databases (PubMed, SCOPUS, PsycINFO, and CINAHL) from database inception until October 2017. Included articles were peer-reviewed, published in English, and quantitatively examined the association between R/S and QOL. We assessed the methodological quality of each included study.

Results The 15 articles included were published between 2002 and 2017. Most studies were conducted in the US and enrolled patients with heart failure. Sixteen dimensions of R/S were assessed with a variety of instruments. QOL domains examined were global, health-related, and disease-specific QOL. Ten studies reported a significant positive association between R/S and QOL, with higher spiritual well-being, intrinsic religiousness, and frequency of church attendance positively related with mental and emotional well-being. Approximately half of the included studies reported negative or null associations. Conclusions Our findings suggest that higher levels of R/S may be related to better QOL among patients with CVD, with varying associations depending on the R/S dimension and QOL domain assessed. Future longitudinal studies in large patient samples with different CVDs and designs are needed to better understand how R/S may influence QOL. More uniformity in assessing R/S would enhance the comparability of results across studies. Understanding the influence of R/S on QOL would promote a holistic approach in managing patients with CVD.
\end{abstract}

Keywords Religiosity · Spirituality · Quality of life · Global QOL · Health-related QOL · Cardiovascular disease

Electronic supplementary material The online version of this article (https://doi.org/10.1007/s11136-018-1906-4) contains supplementary material, which is available to authorized users.

Hawa O. Abu

Hawa.Abu@umassmed.edu

1 Department of Quantitative Health Sciences, University of Massachusetts Medical School, 368 Plantation Street, Worcester, MA 01605, USA

2 Centers for Behavioral and Preventive Medicine, The Miriam Hospital, Providence, RI 02903, USA

3 Department of Epidemiology, Brown School of Public Health, Providence, RI 02903, USA

4 Warren Alpert School of Medicine \& School of Public Health, Brown University, Providence, RI 02903, USA

\section{Introduction}

Cardiovascular disease (CVD) is the leading cause of morbidity and mortality worldwide, with an estimated 17.7 million deaths from CVD in 2015 [1]. Patients with CVD experience numerous physical symptoms including fatigue, dyspnea, or chest pain, which affects their physical, emotional, and social well-being with significant impairment in quality of life (QOL) [2]. While current strategies for the management of patients with CVD are designed to reduce morbidity and prolong survival, treatment should also be focused on improving patient's QOL by reducing their symptoms, optimizing life's daily functions, and overall well-being [2, 3]. Cardiac rehabilitation programs involving lifestyle modification, psychological interventions, education, and counseling have been shown to limit the adverse physiologic and psychologic effects associated with cardiac illness and enhance patient's QOL [4]. 
The World Health Organization defines QOL as 'a broad ranging concept affected in a complex way by the person's physical health, psychological state, level of independence, social relationships and their relationship to salient features of their environment' [5]. Global QOL broadly assesses the overall impact of disease on an individual's life, while health-related QOL (HRQOL) focuses on the impact of health conditions and their symptoms on patients' well-being [6]. Prior studies in patients with CVD have identified QOL as a sensitive patient-reported outcome measure of various intervention strategies [7], as an independent determinant of survival among patients with CVD [8,9], and have reported a gradual decline in QOL with increasing number of CVD risk factors present $[10,11]$.

There is no consensus as to the definitions of "religiosity" or "spirituality." For purposes of this systematic review, we have utilized working definitions of religiosity/spirituality $(\mathrm{R} / \mathrm{S})$ used in the prior literature $[12,13]$. Religious practices and spiritual beliefs influence coping mechanisms in dealing with various chronic illnesses [14-16]. In many patients with CVD, R/S are important and highly personal aspects of their disease experience and provide vital strategies for coping [17]. Studies on the relationship between R/S and QOL among patients with various forms of CVD have, however, demonstrated mixed results. While several reviews have examined factors associated with QOL in patients with CVD $[18,19]$, the association between R/S and global or HRQOL among patients with CVD has received limited attention.

The objective of this systematic review is to summarize and critically appraise available evidence on the association between R/S and QOL in patients with CVD. Understanding this relationship may help in developing intervention strategies to promote spiritual well-being and to optimize QOL in patients with chronic CVD.

\section{Methods}

This review was registered in the international prospective registry of systematic reviews PROSPERO (identification \#: CRD42017076970) and conducted in accordance with the Preferred Reporting Items for Systematic Reviews and Meta-Analyses (PRISMA) guidelines [20].

\section{Search strategy}

We searched four electronic databases (PubMed, SCOPUS, PsycINFO, and Cumulative Index to Nursing and Allied Health Literature (CINAHL)) from database inception with no constraints on publication year. All searches were conducted between September 15, 2017 and October 20, 2017. Two reviewers (H.O.A and C.U) worked in conjunction with two medical research librarians to create a search algorithm that used Medical Subject Headings (MeSH) terms and key words related to "religiosity" and "spirituality" (including related terms religious, religiousness, and spiritual) in combination with "quality of life" (and its associated synonyms HRQOL and well-being), and "cardiovascular disease" (with related terms acute myocardial infarction, acute coronary syndrome, congenital heart disease, rheumatic heart disease, heart failure, and cardiac surgery). The reference sections of eligible full-text articles were examined to identify additional studies suitable for inclusion. The full search algorithm is presented in an electronic supplementary material (Online Resource 1).

\section{Eligibility criteria}

We included only full-text peer-reviewed articles published in English that provided quantitative data with no restriction on study design (observational, randomized controlled trials). Qualitative studies, case reports, and reviews were excluded. Studies of patients with various forms of CVD including heart failure, acute myocardial infarction, coronary heart disease, atrial fibrillation, and congenital heart disease were included. The study population included patients of all ages, at different stages of their care (in-hospital, community dwelling, rehabilitation), and those who received any form of cardiac treatment (medical or surgical). Studies were included if they specifically assessed patient's R/S and assessed either patient's HRQOL, global QOL, or disease-specific QOL as the primary study outcome. The included studies had to assess the direct relationships between R/S and QOL, and studies that examined R/S and QOL as potential mediators were excluded from further evaluation.

\section{Review process}

Study eligibility was assessed by an initial review of the article title followed by a review of the abstract. Full-text publications were subsequently retrieved of eligible articles and those that met our inclusion criteria were retained for data abstraction. One reviewer (H.O.A) independently conducted the reviews, while another reviewer (E.D) determined the appropriateness of final article inclusion. The two reviewers (H.O.A and E.D) met weekly to discuss the eligibility of included studies, and the inter-rater agreement between both reviewers was calculated using Cohen's Kappa statistic [21]. Any discrepancies related to article eligibility were discussed and resolved with reference to the explicit eligibility criteria. If no consensus was reached, a co-author (C.U) provided final judgement about article inclusion or exclusion. 


\section{Data extraction}

A standardized form was used to obtain relevant information from eligible articles including publication date, authors, country of origin, study design, recruitment, completion rates, sample size, and baseline characteristics of the study population. Detailed information was obtained regarding the measures of QOL and R/S including the scale used, number of items, dimensions captured, and the scoring system. The statistical measure(s) of association between R/S and the respective QOL measures were obtained. Two authors (H.O.A and E.D) completed the data extraction process independently.

\section{Study quality assessment}

The methodological quality of identified studies was critically appraised using a revised version of the Downs and Black quality rating scale [22]. The Downs and Black scale was originally developed to assess quality in clinical trials with a checklist consisting of 27 items and a maximum score of 32 points. Similar to prior systematic reviews [23, 24], we revised the scale to allow for the assessment of observational studies. The modified checklist comprised 13 items with a maximum score of 14 for assessing cross-sectional studies, and 18 items with a maximum score of 19 for longitudinal studies. For each study, a quality score (in percentages) was obtained by dividing the number of points earned by the total number the study was eligible to receive based on appropriate reporting of study objectives, methods, results, and validity. Given the limited number of studies identified in this review, no exclusions were based on the quality assessment. Results of the methodological quality assessment are available in an electronic supplementary material (Online Resource 2).

\section{Data synthesis}

The included studies were too heterogeneous for a metaanalysis to be conducted. Heterogeneity between studies was observed in the varying approaches used to assess R/S, ranging from the different instruments used across studies to multiple dimensions of $\mathrm{R} / \mathrm{S}$ examined; these issues have been acknowledged in prior systematic reviews $[25,26]$. We provide a qualitative synthesis of the results obtained from the studies identified in our review.

\section{Results}

\section{Study selection}

Our database search retrieved 623 potentially relevant studies, from which 229 duplicates were removed. Following title and abstract review, 360 articles were excluded leaving 34 full-text articles to be screened for eligibility. We excluded 19 full-text articles that did not measure QOL or R/S, did not statistically assess the association between $\mathrm{R} / \mathrm{S}$ and $\mathrm{QOL}$, or treated R/S or QOL as mediators. The remaining 15 articles were included in this review. Agreement between the two reviewers on the selection of full-text articles was high (Cohen's $\kappa$ 0.90). No eligible articles were identified from the reference lists of included studies. Of the 15 publications in this review, four used data derived from a single cohort study [27-30], while two articles used data from another cohort investigation [31, 32]. Publications using data from the same cohort study were considered individually due to their varying study objectives and findings. Detailed results of our screening process are presented in Fig. 1.

\section{Description of included studies}

\section{Study design and setting}

The fifteen studies included in this review were published between 2002 and 2017; most were conducted in the US ( $n=12,[27-38])$ while others were carried out in Greece $(n=1,[39])$, Iran $(n=1,[40])$, and Korea $(n=1,[41])$. All identified studies were observational; two-thirds used a cross-sectional design $(n=9,[30,33-35,37-41])$, while six studies used a longitudinal design [27-32]. Study followup periods ranged from 3 months [27-29, 32] to 2 years [31]. Study sample sizes ranged from 58 to 163 patients with varying manifestations of CVD.

\section{Patient characteristics}

In all studies except for one, patients were typically middle aged or older with the mean age at the time of study enrollment ranging from 53 to 67 years. The patient populations were predominantly male (range 48-79\%) and married (range $50-91 \%$ ). The only exception was a study that included adult patients with congenital heart disease [41]; the mean age of these patients at study enrollment was 26.5 years and only $10.6 \%$ were married. Patient's racial distribution was reported only in US-based studies with a predominance of non-Hispanic Whites (range 47-100\%). Nine publications $[27-33,39,40]$ reported religious affiliation. In the Greek study [39], all participants were Orthodox Christians; while in the Iranian study [40], all participants were Muslims. In the seven US-based studies that provided data on religious affiliation [27-33], most participants were Protestants (range 62-72\%) or Catholics (range 16-29\%). Eleven of the fifteen studies enrolled patients with heart failure $[27-30,33-38,40])$, and the average time since diagnosis varied between 6 months and 6.5 years. One study 


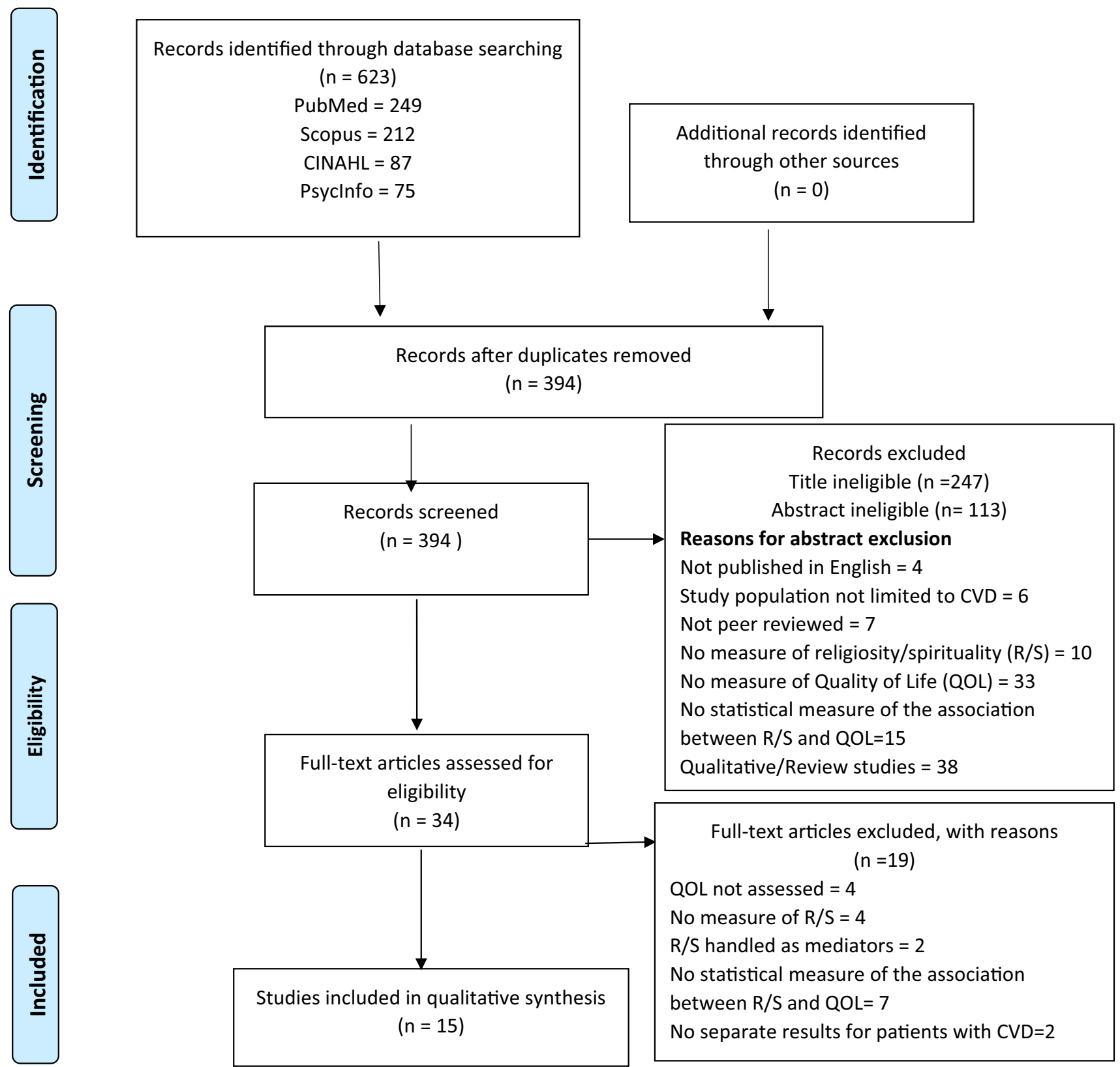

Fig. 1 Flow diagram for systematic review methodology in accordance with PRISMA guidelines

[39] enrolled patients with varying diagnoses of CVD. Other studies included patients with a diagnosis of myocardial infarction [31, 32] and congenital heart disease [41]. Table 1 provides a detailed description of studies included in this systematic review.

\section{Measures of R/S}

The dimensions of R/S assessed in the identified studies included religious attitudes [40], religious, existential, and spiritual well-being [33, 37, 38], religious support [28], spiritual perspectives [34], strength and comfort from religion [35], religious coping [28, 31, 32, 36], church service attendance [39], intrinsic religiousness [39], religious identification and religious struggle [27, 28], spiritual desires and constraints [30], spiritual and religious concerns [32], belief in the afterlife [28], forgiveness [28], and daily spiritual experience $[27,28,30]$. A variety of instruments were used to assess R/S (Table 2) ranging from a simple validated one-item scale [39] to a more complex 29-item scale [42]. Three instruments that assessed R/S were used in more than one study: the 12-item Functional Assessment of Chronic Illness Therapy (FACIT-Sp-12), a validated self-reported measure of overall spiritual 


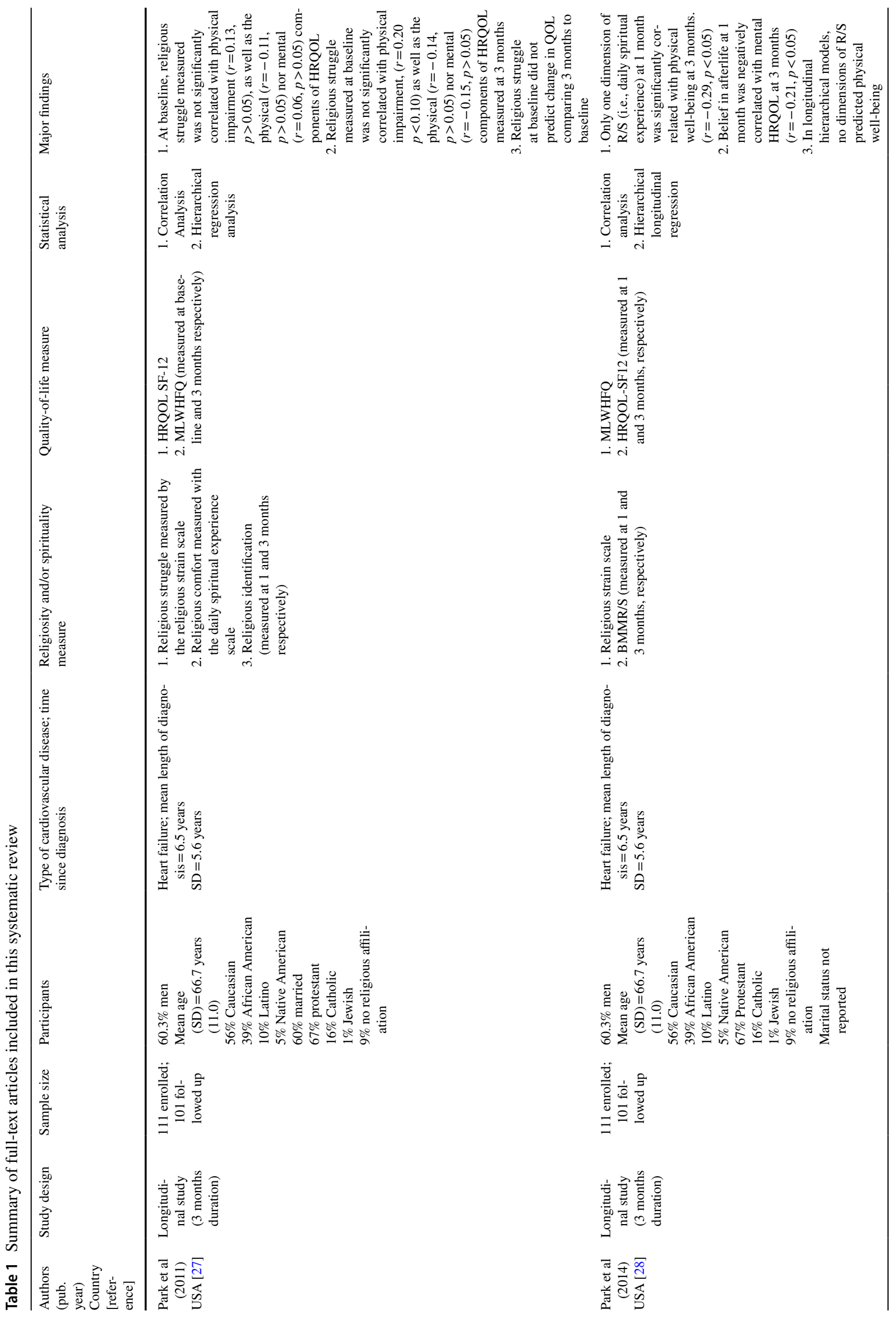




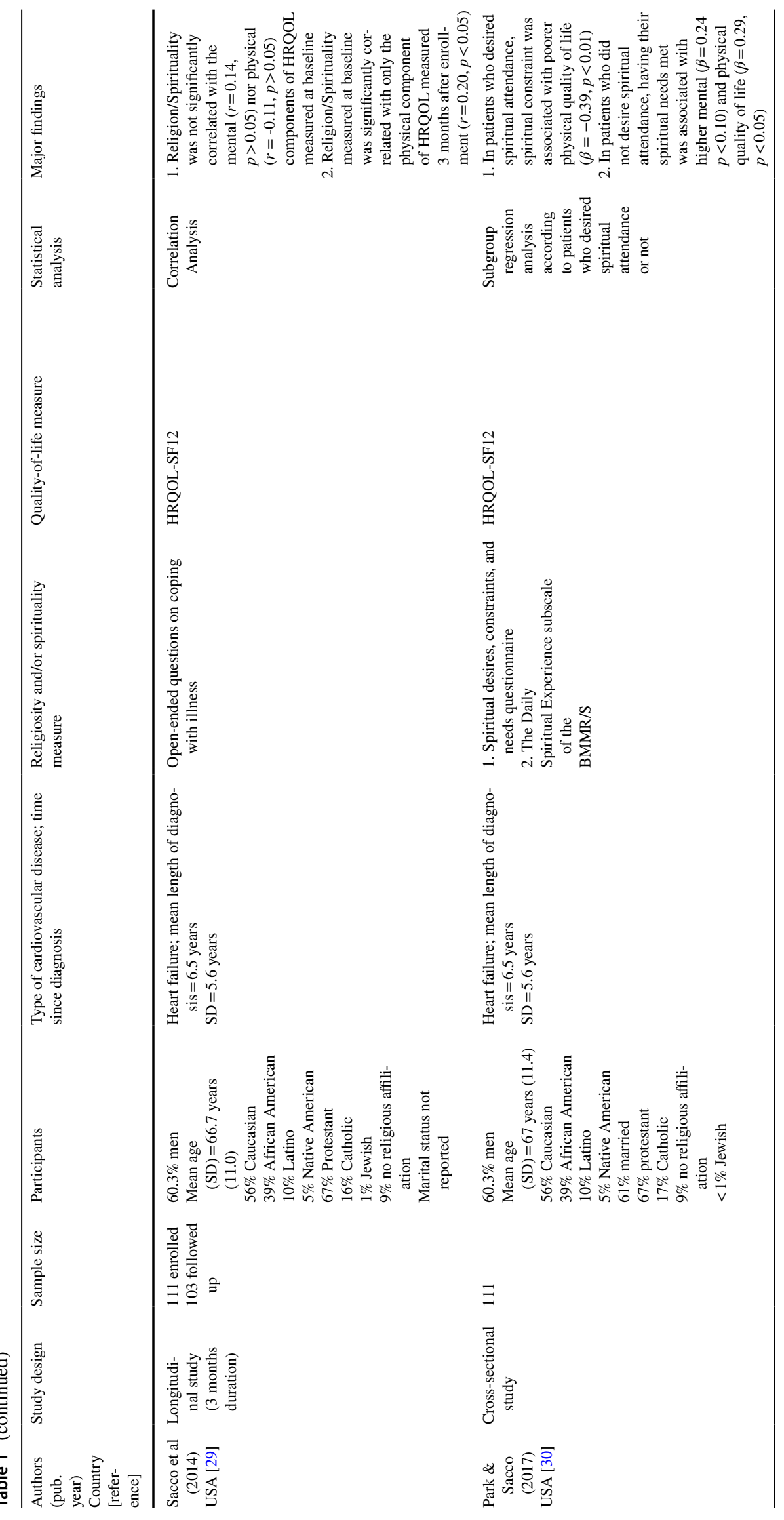




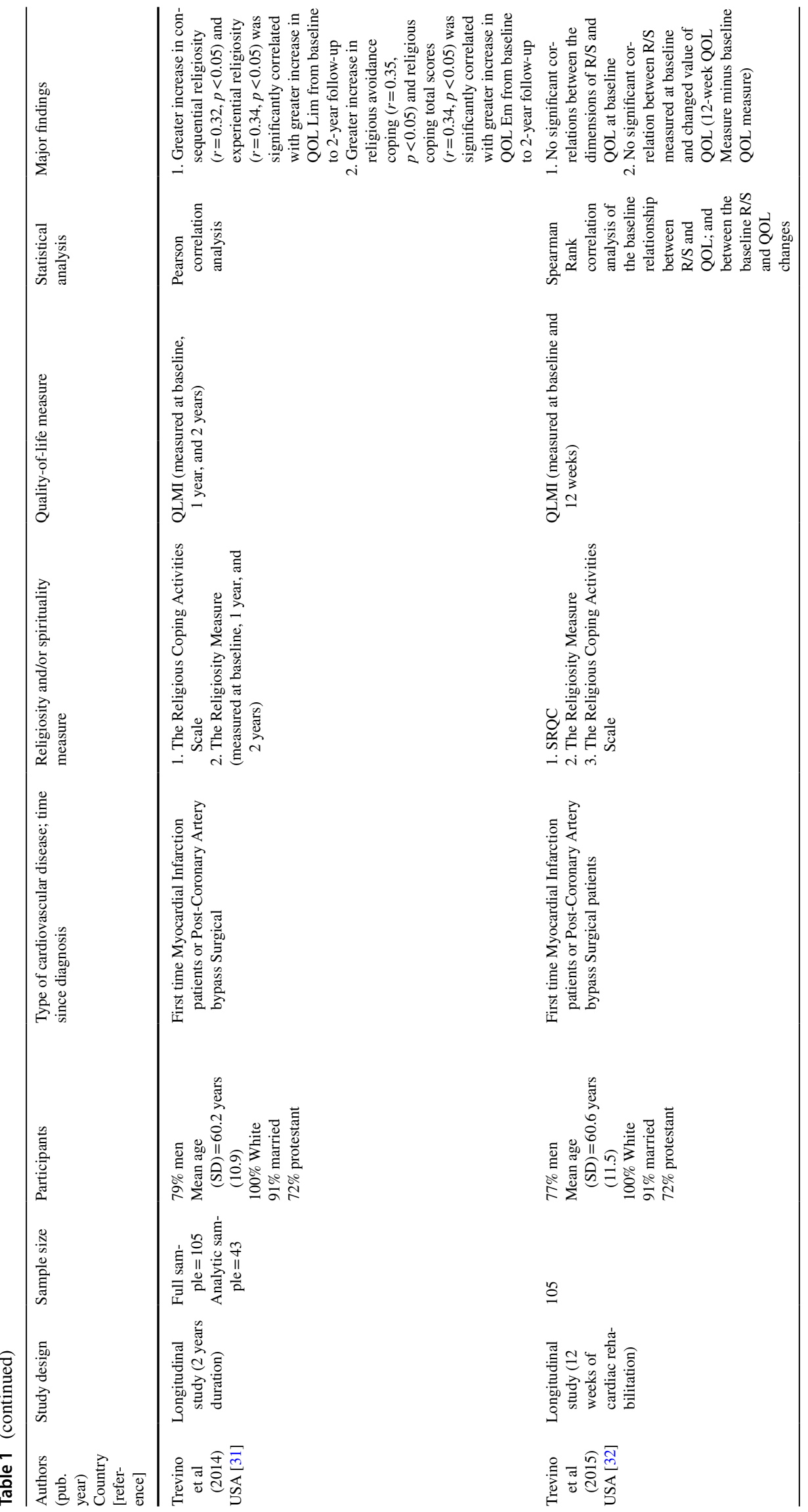




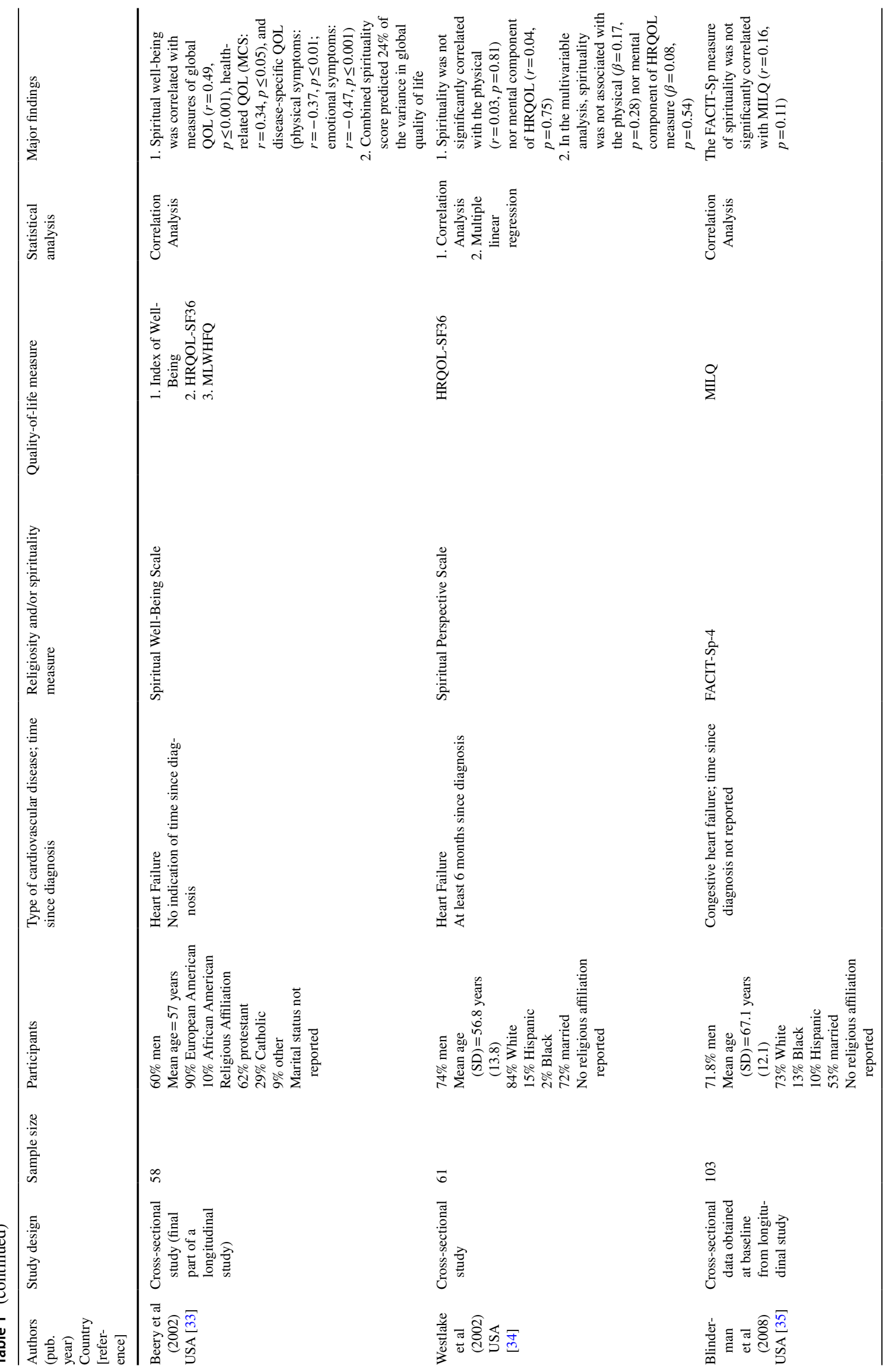




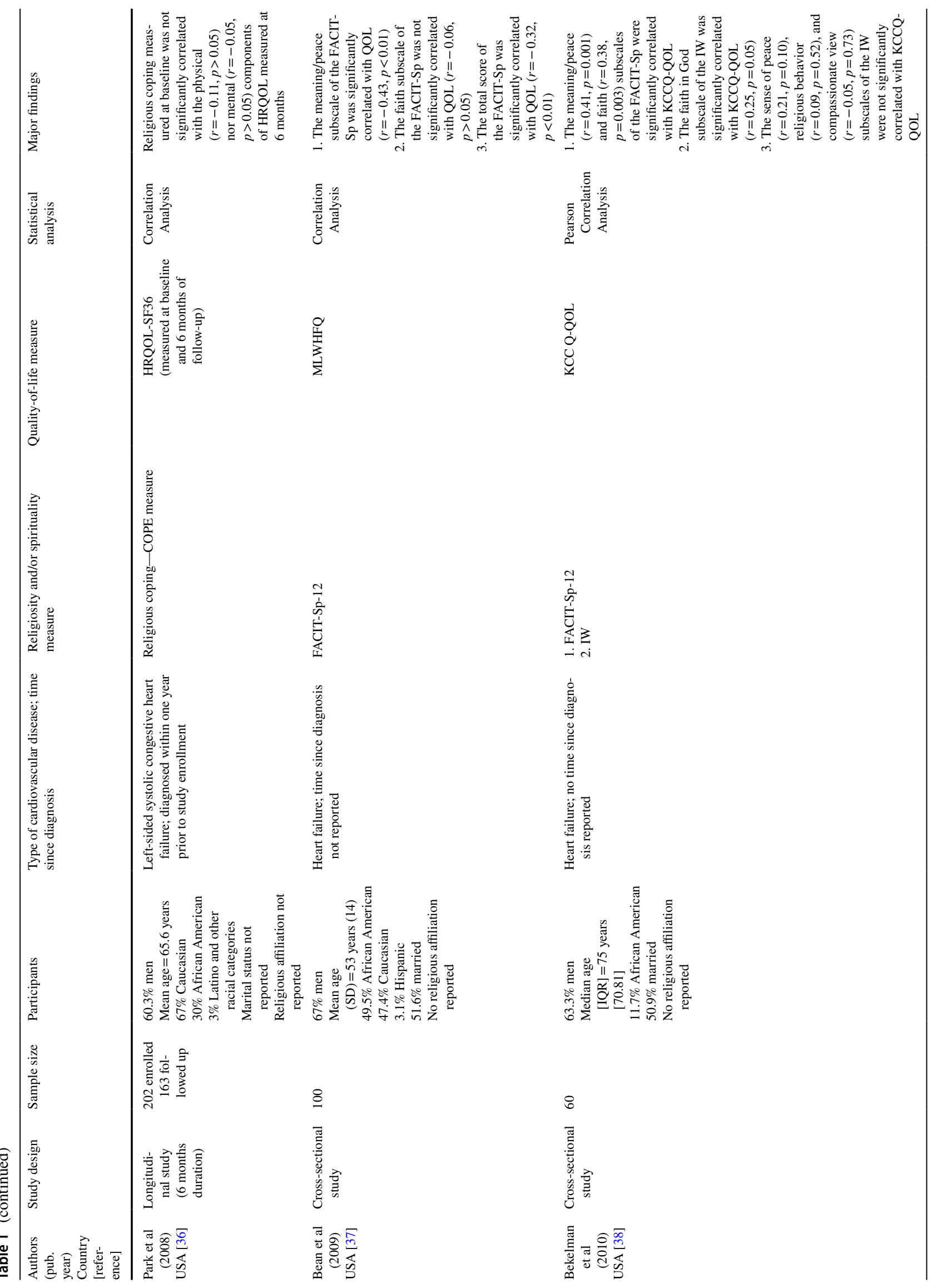




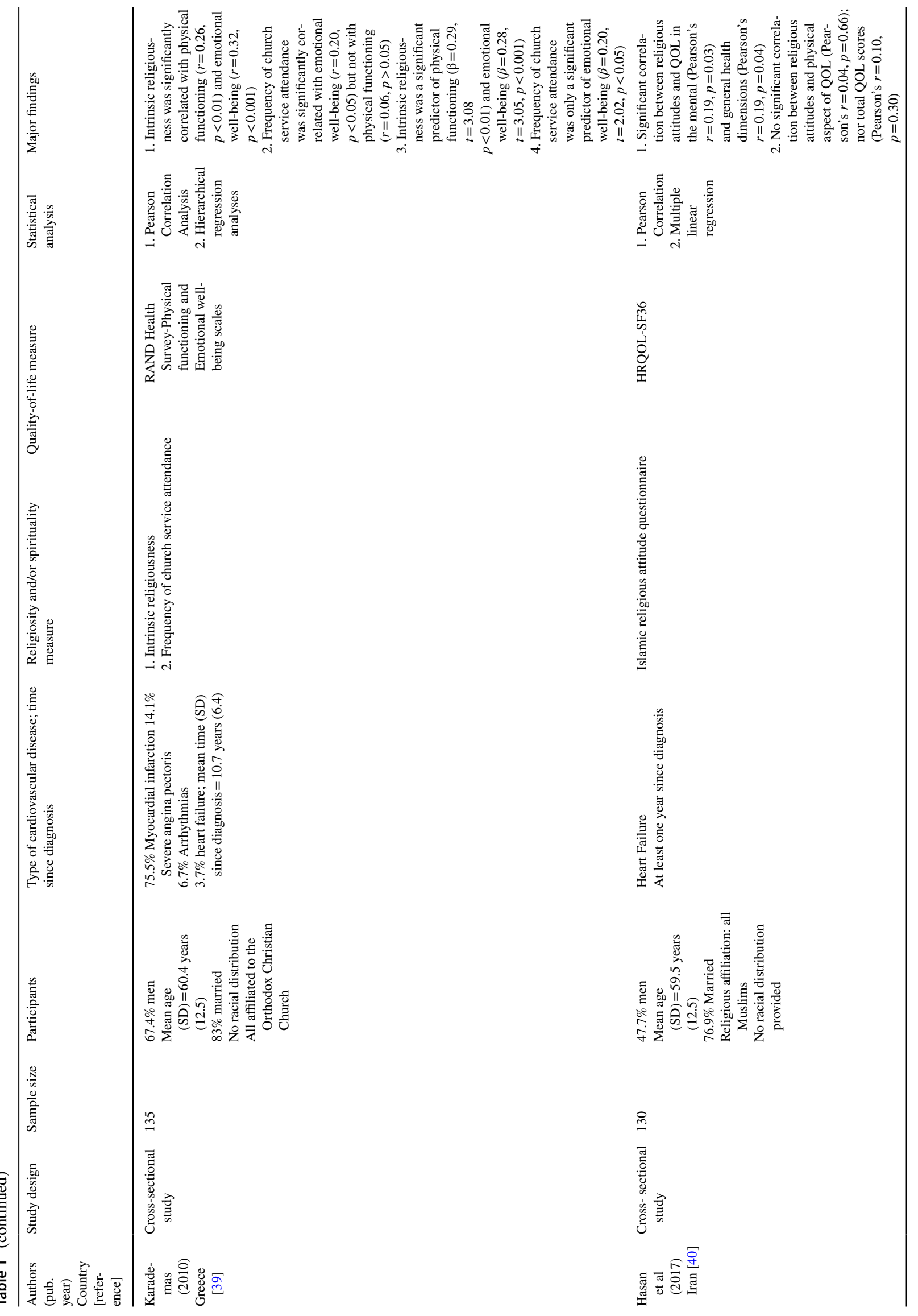




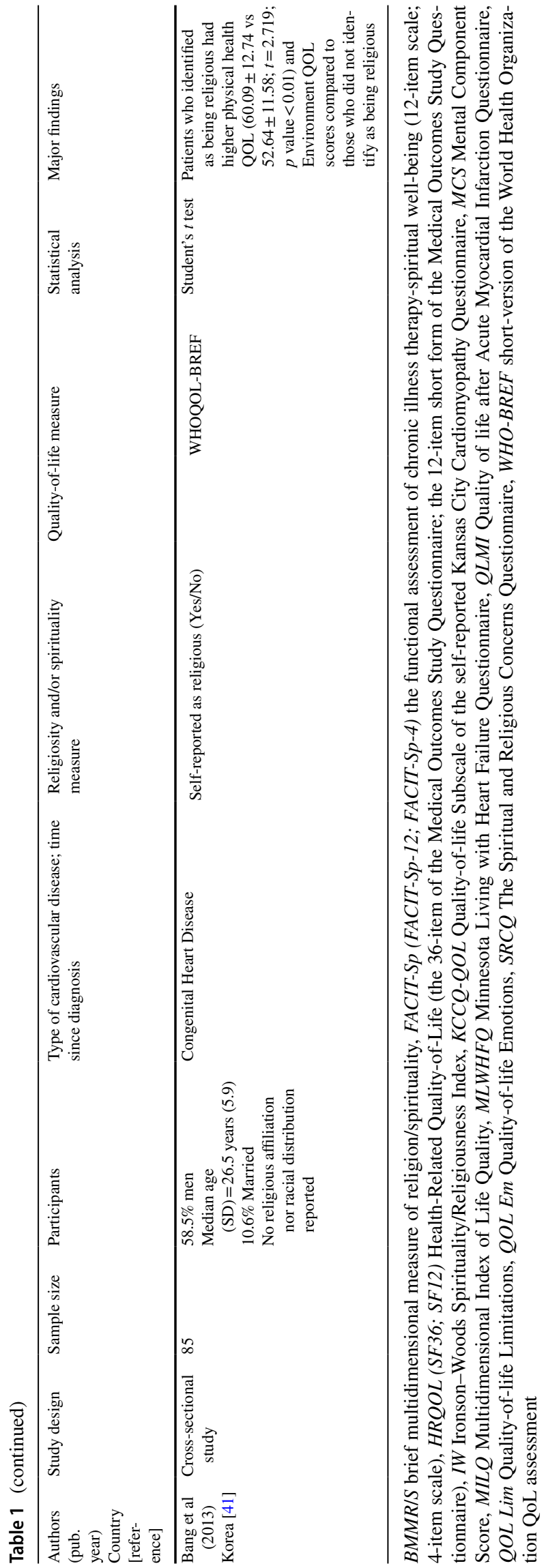

well-being that assesses "Meaning/Peace" and "Faith" [43], the Brief Multidimensional Measure of Religion/ Spirituality (BMMR/S) [44], and the Religious strain scale [45]. Table 2 provides a description of the R/S instruments and scoring systems used in the included studies.

\section{QOL outcomes}

In contrast to the different measures of R/S, the QOL outcomes were more homogenous across studies (Table 3 ). Commonly reported outcomes were global QOL, mental or physical HRQOL, disease-related QOL, and dimensions of functional, emotional, or social well-being. Global QOL was assessed in three studies [33, 35, 41] with a different instrument used in each study: The Index of Well-Being [54], Short-version of The World Health Organization QoL assessment (WHOQOL-BREF) [55], and the Multidimensional Index of Life Quality (MILQ) [56]. Nine studies evaluated patients' HRQOL using three instruments: The 36-item Medical Outcomes Study Questionnaire (SF-36) [57] was used in four studies [33, 34, 36, 40], the 12-item Short Form of the Medical Outcomes Study Questionnaire (SF-12) [58] was used in four studies [27-30], and the RAND 36-item Health Survey [59], a validated instrument adapted from the SF-36 that uses a simpler scoring system, was utilized in one study [39]. Five studies assessed disease-specific QOL with three instruments: The Minnesota Living with Heart Failure (MLHF) Questionnaire [60] in two studies [33, 37], the Quality of Life after Acute Myocardial Infarction (QLMI) [61] in two studies [31, 32], and the Kansas City Cardiomyopathy Questionnaire (KCCQ)-QOL subscale [62] in a single study [38].

\section{Statistical analysis}

Eight studies conducted a correlational analysis only [29, 31-33, 35-38], three studies conducted both correlation and hierarchical regression analyses [27, 28, 39], two studies conducted both correlation and multiple linear regression analyses $[34,40]$, one study utilized only multiple regression analysis [30], and another study used $t$ tests to assess between group differences [41]. Correlation analysis was conducted between R/S and QOL measured at a single time point in cross-sectional studies [33-35, 37-40]. In studies using a longitudinal design, researchers examined the association between R/S measured at baseline and QOL during the course of follow-up [27-29, 31, $32,36]$. Socio-demographic variables commonly adjusted for in the regression analyses included age, gender, race, marital status, and education. 


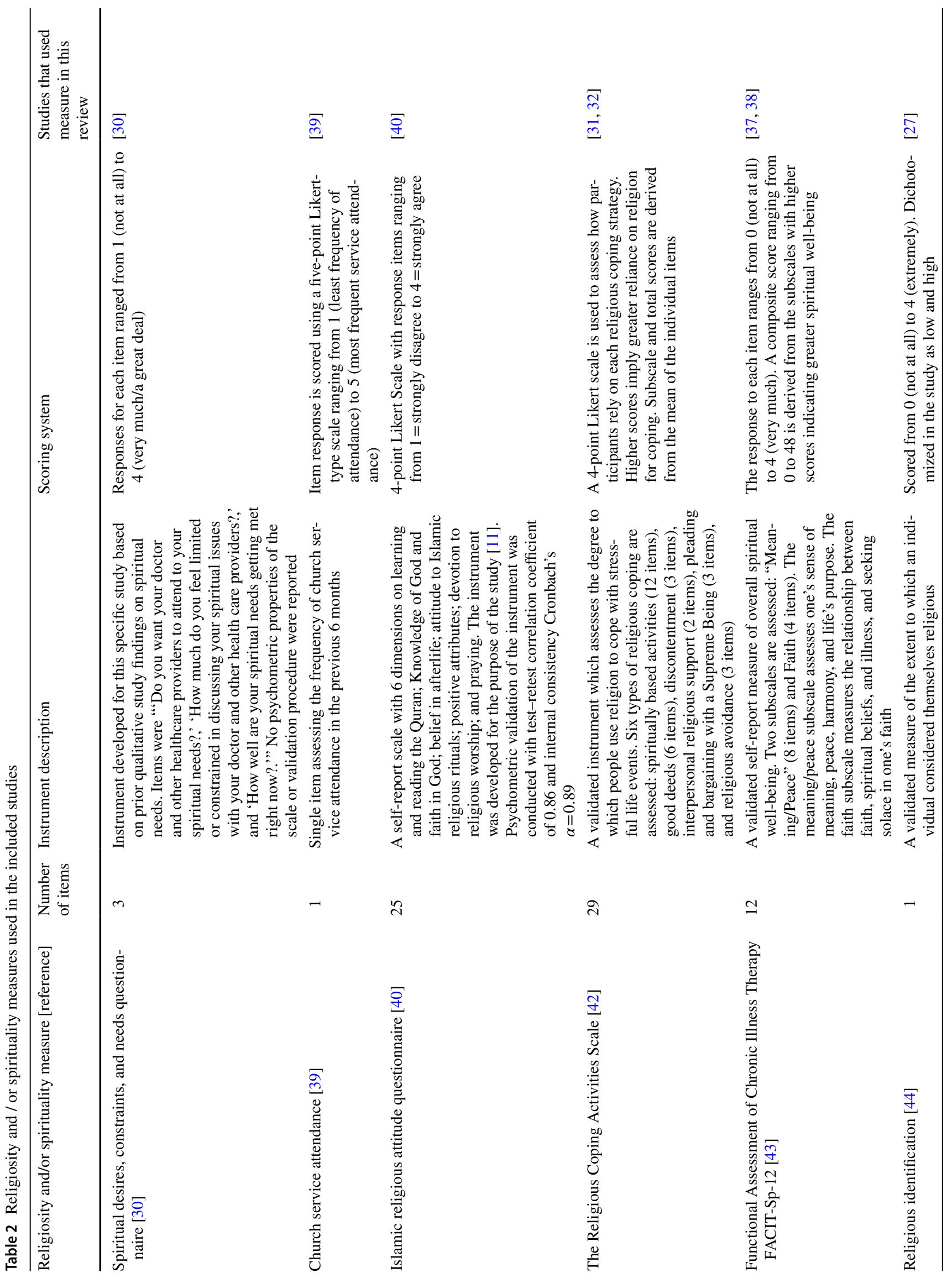




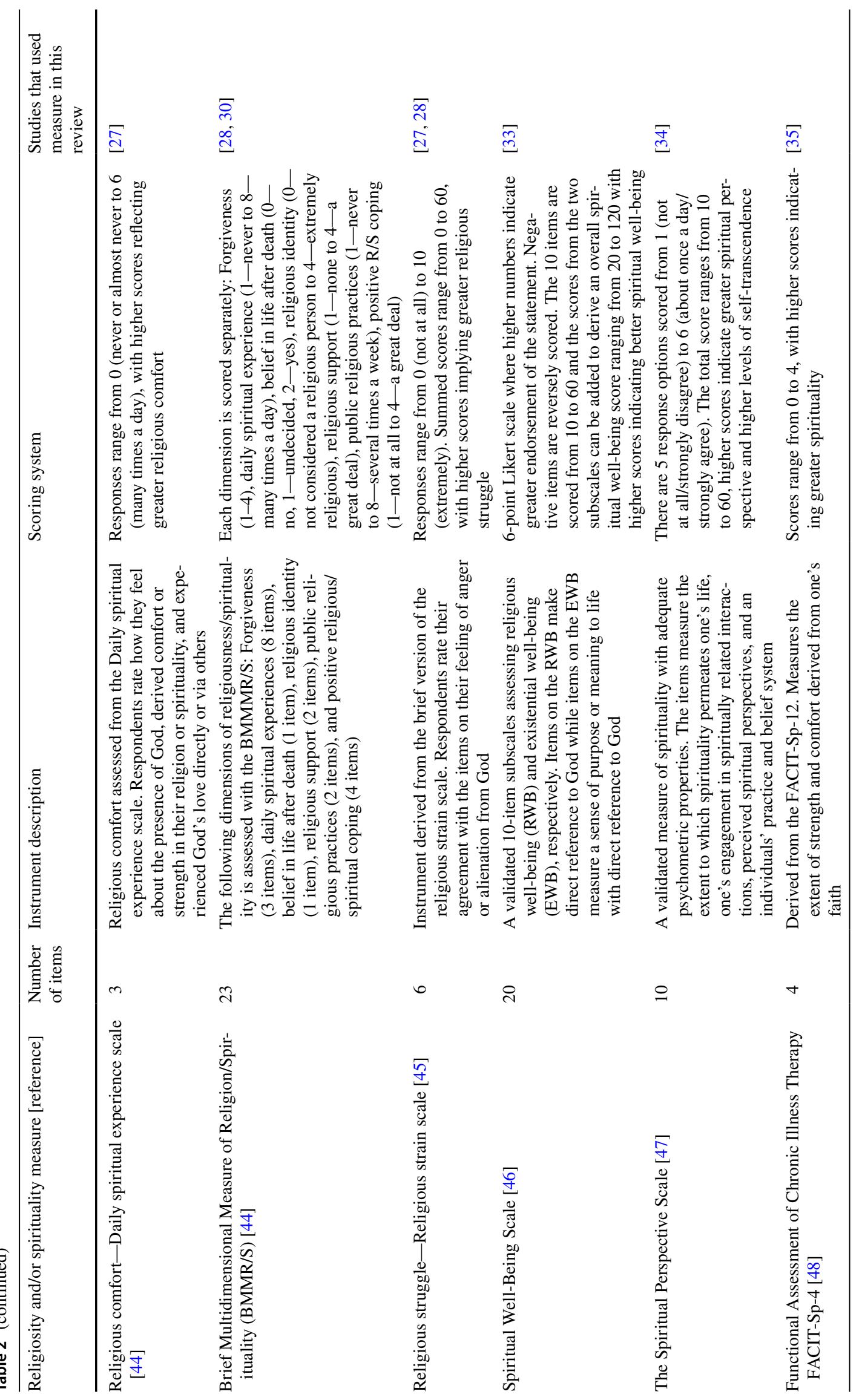




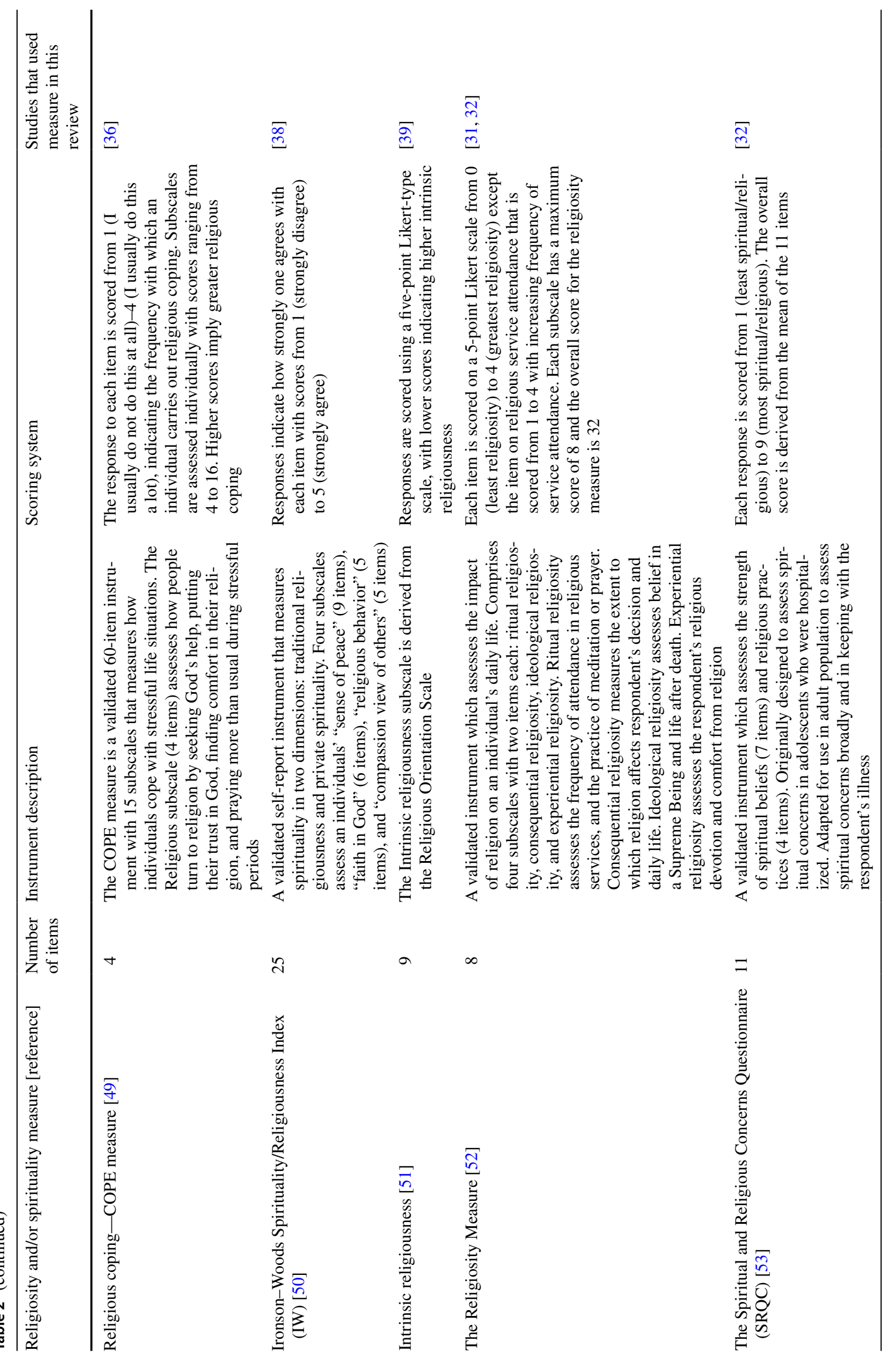




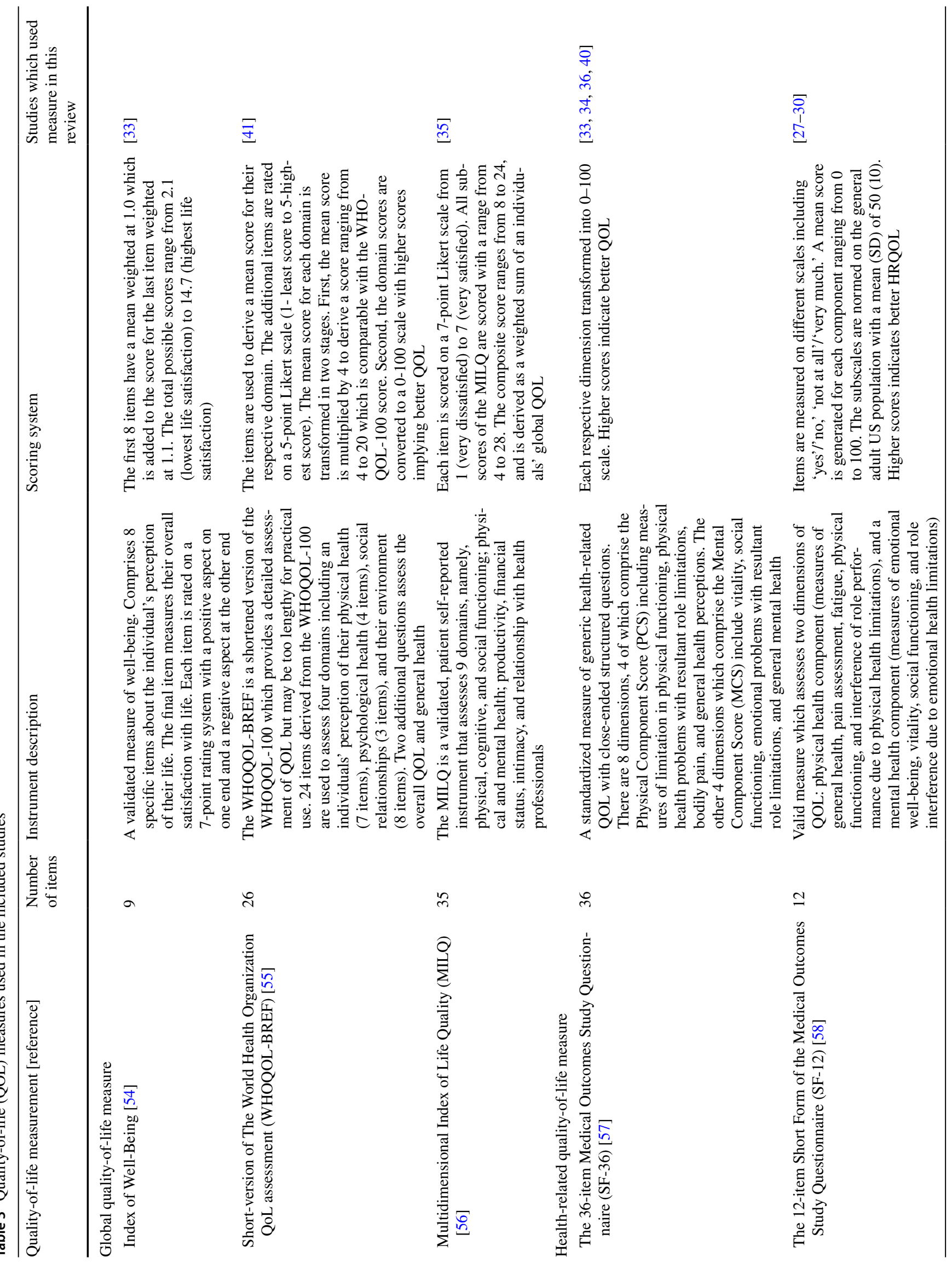




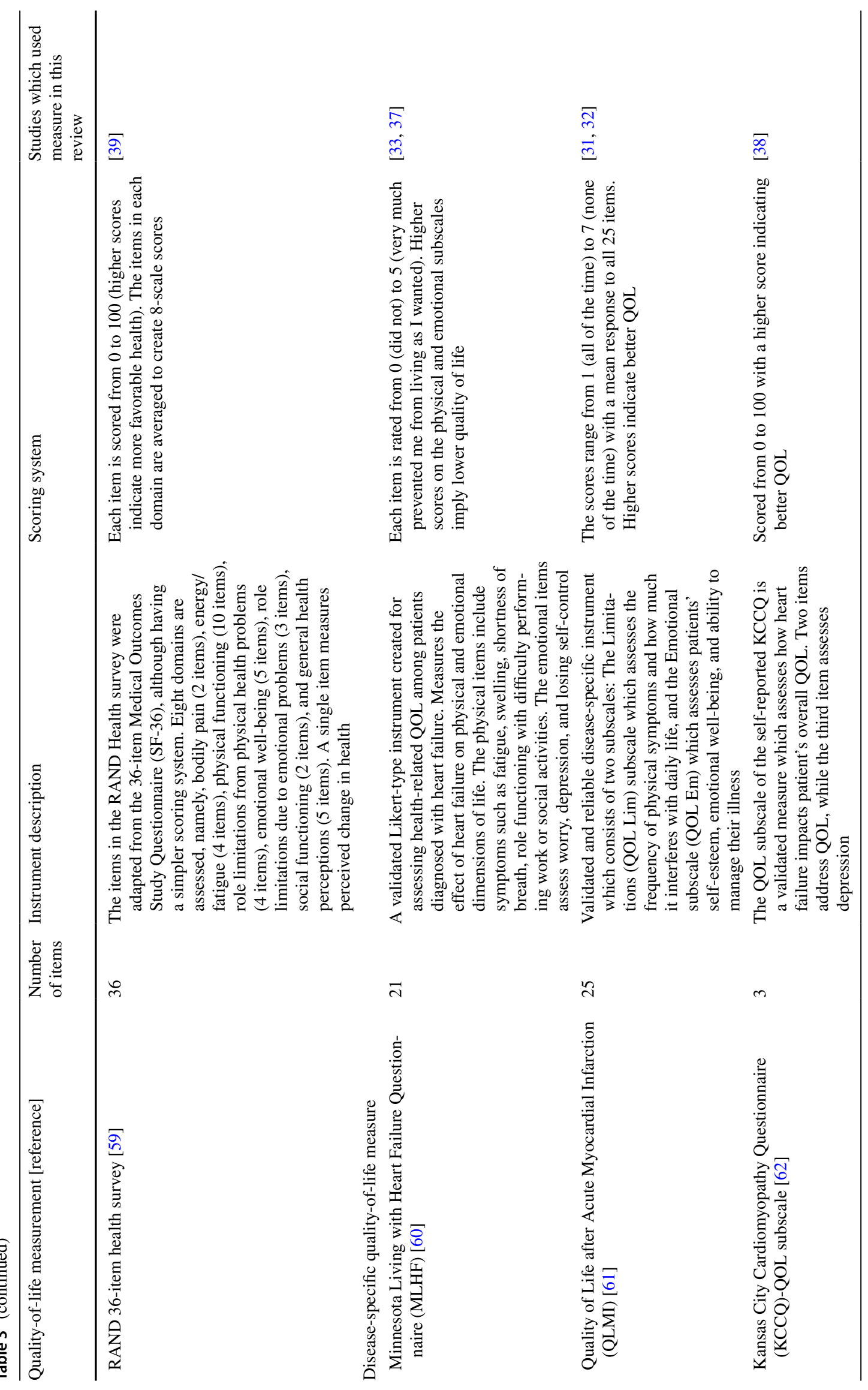




\section{Association between R/S and QOL}

The association between R/S and QOL differed according to the dimension of R/S and QOL domain assessed. We have summarized the principal study findings based on the association between R/S and QOL domain examined (global QOL, HRQOL, and disease-specific QOL), and according to the type of CVD. Results from included studies are detailed in Table 1.

\section{Association between $\mathrm{R} / \mathrm{S}$ and $\mathrm{QOL}$ in patients with heart failure}

Eleven studies examined the association between R/S and QOL in patients with heart failure. Four publications used longitudinal data [27-29, 36], and seven used a cross-sectional design [30, 33-35, 37, 38, 40]. A significant positive association between R/S and QOL was reported in six of the eleven studies [28-30, 33, 38, 40]. The association between $\mathrm{R} / \mathrm{S}$ and QOL domains in patients with heart failure is as follows:

R/S and Global QOL: Spiritual well-being was positively correlated with global QOL measures $(r=0.49, p \leq 0.001)$ [33], while spirituality, as assessed with the FACIT-Sp measure, was not significantly related to global QOL [35].

R/S and HRQOL: Higher daily spiritual experience and having one's spiritual needs met were positively associated with higher physical well-being [28, 30]. Attending to one's spiritual needs, spiritual well-being, and a more religious attitude were positively associated with better mental or emotional well-being [30, 33, 40]. However, belief in the afterlife at 1 month was negatively associated with mental HRQOL at 3 months [28], while spiritual constraint was associated with poorer physical QOL [30]. Spirituality was not associated with the physical or mental components of HRQOL [34]. Neither religious struggle nor religious coping were significantly associated with the mental or physical components of HRQOL at study baseline and during a subsequent follow-up evaluation [27, 36].

R/S and disease-specific QOL: A cross-sectional study assessed patient's spirituality with the FACIT-Sp and Ironson-Woods Spirituality/Religiousness Index (IW) [38]; the meaning/peace and faith subscales of the FACIT-Sp, and the faith in God subscale of the IW were positively correlated with QOL, as assessed with the KCCQ. In contrast, the sense of peace, religious behavior, and compassionate view subscales of the IW were not significantly associated with KCCQ-QOL. Another study found no significant association between the meaning/peace and faith subscales of the FACIT-Sp and QOL as assessed with the MLHF questionnaire [37]. Lower spiritual well-being was negatively associated with poorer physical and emotional symptoms [33].
Association between $\mathrm{R} / \mathrm{S}$ and $\mathrm{QOL}$ in patients with acute myocardial infarction (AMI)

Two longitudinal studies examined the association between $\mathrm{R} / \mathrm{S}$ and disease-specific QOL in patients with AMI [31, 32]. The findings from a study of 105 patients with a first time AMI [31], showed that higher consequential religiosity, experiential religiosity, and religious avoidance coping were significantly associated with increases in QOL from baseline to the 2-year follow-up. In this cohort, no significant association was found between the dimensions of $\mathrm{R} / \mathrm{S}$ and QOL at baseline, and the baseline measure of R/S was not associated with changes in QOL after 12-weeks of cardiac rehabilitation [32].

\section{Association between R/S and QOL in congenital heart disease}

One cross-sectional study examined the association between R/S and global QOL in patients with congenital heart disease [41]. Those who identified as being religious had higher physical and environmental QOL scores (60.1 vs 52.6; $p$ value $<0.01$ ) compared with those who did not identify as being religious.

\section{Association between R/S and QOL in a study with multiple CVD diagnoses}

A cross-sectional study that enrolled patients $(n=135)$ with varying CVD diagnoses (75.5\% myocardial infarction, $14.1 \%$ severe angina pectoris, $6.7 \%$ arrhythmias, and $3.7 \%$ heart failure) examined the association between R/S and HRQOL [39]. Intrinsic religiousness was positively associated with higher emotional and physical well-being, and a higher frequency of church attendance was positively associated with better mental or emotional well-being.

\section{Study quality assessment}

The quality scores of the included studies ranged from 73.7 to $94.7 \%$. All studies clearly reported their objective(s), described study participant characteristics, and their key exposure and outcome variables. With respect to internal validity, only a few studies sufficiently adjusted for potential confounders in the form of a multivariable regression analysis [27, 28, 34, 39, 40]. Five longitudinal studies [27-29, 31, 36] adequately reported the number of participants recruited, those lost to follow-up, and reasons for attrition. Most studies addressed the representativeness of their study sample and the generalizability of their 
findings to the population from which the study subjects were selected.

\section{Discussion}

In this systematic review, we found evidence for an association between R/S and QOL among patients with CVD. This association varied depending on the dimension of $\mathrm{R} / \mathrm{S}$ and QOL domain assessed. Ten of the fifteen studies identified in this review reported a significant positive association between R/S and QOL, and approximately half of the studies reported negative or null associations. The majority of included studies were conducted among patients with heart failure.

Prior studies have posited a variety of mechanisms by which R/S influences QOL in patients with chronic conditions. Religiousness has been shown to enhance self-esteem, generate positive emotions, and promote positive selfcare practices by encouraging individuals to refrain from unhealthy lifestyle practices, which in turn fosters well-being [63-65]. R/S may favorably influence an individual's QOL by fostering a deeper sense of meaning when faced with life-threatening or chronic debilitating conditions [66]. Our findings suggest that R/S is associated with QOL, as intrinsic religiousness, spiritual well-being, and attending to one's spiritual needs were related to better physical, mental, and emotional functioning. On the other hand, spiritual constraint and lower spiritual well-being were associated with poorer physical and emotional well-being.

\section{R/S and QOL}

We observed considerable heterogeneity in the R/S measures utilized, reflective of the varying dimensions of $\mathrm{R} / \mathrm{S}$ assessed in research and the general lack of consensus in defining R/S [67]. Most of the included studies utilized already existing validated scales, whereas one recent study designed their $\mathrm{R} / \mathrm{S}$ questionnaire for purposes of assessing religious attitudes [40]. This latter study provided a detailed description of their instrument validation process and had a high-quality rating in our methodological assessment.

Upwards of sixteen dimensions of R/S were assessed across studies with religious coping being the most commonly assessed aspect. In patients diagnosed with an initial AMI or after coronary artery bypass surgery, higher religious coping was associated with better emotional QOL over a 2-year follow-up period. In contrast, no association was observed between religious coping and physical/mental well-being in patients living with heart failure at 6 months of follow-up. These findings reflect how R/S may differentially influence QOL depending on the domain assessed, patient's clinical diagnosis, and the duration of follow-up in assessing the impact of one's R/S on their QOL since shorter follow-up periods may not sufficiently allow for R/S to influence health outcomes. Furthermore, reverse causation and residual confounding may explain these differences observed in the various studies included in this review. In a study [28] that examined seven dimensions of R/S (forgiveness, daily spiritual experiences, belief in afterlife, religious identity, religious support, public practices, and positive RS coping), only moderate correlations were found between the dimensions suggesting that they each represent a unique aspect of one's religious/spiritual experience, and that each $\mathrm{R} / \mathrm{S}$ dimension may have a distinct role in the relationship between R/S and patient's QOL domains.

We observed considerably greater uniformity in the QOL outcome measures examined in this review, with the three major domains of global, health-related, and disease-specific QOL assessed.

\section{Summary of the Literature}

A majority of studies included in this review $[n=11]$ were conducted between 2010 and 2017, indicative of an increasing awareness of the relationship between R/S and patient's QOL. Most of the identified studies $[n=11]$ enrolled patients with heart failure, which may be attributable to the worldwide rise in the magnitude of heart failure and its considerable morbidity and mortality, and impact on patient's QOL due to its physical and emotional symptoms [68, 69]. However, future research is needed among patients with varying manifestations of underlying CVD, including acute and chronic forms of heart disease, which may have a considerable impact on patient's QOL.

Most of the included studies [ $n=12]$ were conducted in the US, and the study participants were predominantly non-Hispanic Whites and middle-older aged persons, which limits the generalizability of the study findings to ethnic minority groups and younger individuals. There was an overrepresentation of studies with small sample sizes, short follow-up duration, or the use of a cross-sectional design, which limits the conclusiveness of our review. Results from the methodological quality assessment revealed that included studies had moderate- to high-quality ratings, which lends some credence to the reliability of our findings.

\section{Strengths and limitations of the current systematic review}

To our knowledge, this is the first systematic review to examine the association between R/S and QOL in patients with CVD. From a self-evaluation of our review using the AMSTAR tool for assessing systematic review quality [70], we obtained a score of 10 out of a maximum of 11 
points. The one point not credited to this review was due to our inability to investigate possible publication bias with a funnel plot as we would have required a uniform measure of effect, which was impossible due to heterogeneity in the assessment of R/S across the included studies.

Several limitations of our review exist. First, we excluded non-English articles, likely leading to publication bias. Our initial search of the electronic databases did not exclude studies based on publication language; however, only four studies in foreign languages were identified. Second, we suggest caution in interpreting the synthesized results from this review, as causal inferences on the association between R/S and QOL cannot be made from observational studies which are susceptible to potential confounding by unmeasured or inadequately measured variables, and cross-sectional studies do not account for temporality. Most included studies were conducted among patients with heart failure, which may have limited the generalizability of our findings. Lastly, most identified studies were conducted in the US, which may not adequately capture R/S and cultural impact on QOL from a global perspective.

\section{Research and clinical implications}

Future research should be conducted in patients with different CVD conditions to better understand how R/S may influence their QOL. Longitudinal studies in larger patient samples are needed to better understand how R/S may affect QOL over varying follow-up periods, as it is unclear whether any associations observed over the shortterm persist on a longer-term basis. Future studies should evaluate how patients may turn to or away from R/S in periods of illness and stress, how this might influence their QOL, and identify those in need of clerical intervention for a more holistic approach in patient management. In addition, there is a need for uniformity in assessing R/S to ensure more reliable and comparable results across studies. Furthermore, advanced analytic techniques, such as propensity scoring and instrumental variables to address confounding in observational studies should be explored.

The findings from this review reveal that certain dimensions of R/S are likely associated with patient's QOL. Healthcare providers need to consider the influence of $\mathrm{R} / \mathrm{S}$ on patient's QOL, as this may also influence patient engagement with their treatment and long-term outcomes.

Acknowledgements We thank Catherine Carr and Victoria Rossetti for their assistance in developing the search strategy for the electronic databases used in this systematic review.

Funding This study did not receive any funding.

\section{Compliance with ethical standards}

Conflict of interest The authors have no conflict of interest to disclose.

Ethical approval This article does not contain any studies with human participants performed by any of the authors.

Open Access This article is distributed under the terms of the Creative Commons Attribution 4.0 International License (http://creativeco mmons.org/licenses/by/4.0/), which permits unrestricted use, distribution, and reproduction in any medium, provided you give appropriate credit to the original author(s) and the source, provide a link to the Creative Commons license, and indicate if changes were made.

\section{References}

1. World Health Organization. (2017). Cardiovascular diseases. [Fact Sheet]. Retrieved September 27, 2017, from http://www.who.int/ mediacentre/factsheets/fs317/en/.

2. Moryś, J. M., Bellwon, J., Höfer, S., Rynkiewicz, A., \& Gruchała, M. (2016). Quality of life in patients with coronary heart disease after myocardial infarction and with ischemic heart failure. Archives of Medical Science, 12(2), 326-333.

3. Wenger, N. K., Mattson, M. E., Furberg, C. D., \& Elinson, J. (1984). Assessment of quality of life in clinical trials of cardiovascular therapies. American Journal of Cardiology, 54(7), 908-913.

4. Shepherd, C. W., \& Alison, E. W. (2012). Cardiac rehabilitation and quality of life: A systematic review. International Journal of Nursing Studies, 49(6), 755-771.

5. World Health Organization. (1987). WHOQOL: Measuring quality of life. Geneva: WHO. Retrieved September 27, 2017, from http://apps.who.int/iris/bitstream/10665/63482/1/ WHO_MSA_MNH_PSF_97.4.pdf.

6. Burns, T. M., Graham, C. D., Rose, M. R., \& Simmons, Z. (2012). Quality of life and measures of quality of life in patients with neuromuscular disorders. Muscle and Nerve, 46, 9-25.

7. Cepeda-Valery, B., Cheong, A. P., Lee, A., \& Yan, B. P. (2011). Measuring health related quality of life in coronary heart disease: the importance of feeling well. International Journal of Cardiology, 149, 4-9.

8. Kato, N., Kinugawa, K., Seki, S., Shiga, T., Hatano, M., Yao, A., et al. (2011). Quality of life as an independent predictor for cardiac events and death in patients with heart failure. Circulation Journal, 75, 1661-1669.

9. Issa, S. M., Hoeks, S. E., Scholte op Reimer, W. J. M., Van Gestel, Y. R., Lenzen, M. J., Verhagen, H. J., et al. (2010). Health-related quality of life predicts long-term survival in patients with peripheral artery disease. Vascular Medicine, 15, 163-169.

10. Xie, J., Wu, E. Q., Zheng, Z. J., Sullivan, P. W., Zhan, L., \& Labarthe, D. R. (2008). Patient-reported health status in coronary heart disease in the United States: Age, sex, racial, and ethnic differences. Circulation, 118, 491-497.

11. De Smedt, D., Clays, E., Annemans, L., Doyle, F., Kotseva, K., Pająk, A., et al. (2013). Health related quality of life in coronary patients and its association with their cardiovascular risk profile: Results from the EUROASPIRE III survey. International Journal of Cardiology, 168, 898-903.

12. Ross, L. (1995). The spiritual dimension: Its importance to patients' health, well-being and quality of life and its implications for nursing practice. International Journal of Nursing Studies, 32, $457-468$. 
13. Koenig, H. G., McCullough, M., \& Larson, D. (2001). Handbook of religion and health. New York: Oxford University Press.

14. Van Groenestijn, A. C., Kruitwagen-van Reenen, E. T., VisserMeily, J. M. A., van den Berg, L. H., \& Schröder, C. D. (2016). Associations between psychological factors and health-related quality of life and global quality of life in patients with ALS: A systematic review. Health and Quality of Life Outcomes, 14, 107.

15. Yamout, B., Issa, Z., Herlopian, A., El Bejjani, M., Khalifa, A., Ghadieh, A. S., et al. (2013). Predictors of quality of life among multiple sclerosis patients: A comprehensive analysis. European Journal of Neurology, 20, 756-764.

16. Paiva, C. E., Paiva, B. S., de Castro, R. A., de Pádua Souza, C., de Paiva Maia, Y. C., Ayres, J. A., et al. (2013). A pilot study addressing the impact of religious practice on quality of life of breast cancer patients during chemotherapy. Journal of Religion and Health, 52, 184-193.

17. Najafi Ghezeljeh, T., \& Emami, A. (2014). Strategies for recreating normal life: Iranian coronary heart disease patients' perspectives on coping strategies. Journal of Clinical Nursing, 23, 2151-2160.

18. Yaghoubi, A., Tabrizi, J. S., Mirinazhad, M. M., Azami, S., Naghavi-Behzad, M., \& Ghojazadeh, M. (2012). Quality of life in cardiovascular patients in iran and factors affecting it: A systematic review. Journal of Cardiovascular and Thoracic Research, 4(4), 95-101.

19. Muhammad, I., He, H. G., Kowitlawakul, Y., \& Wang, W. (2016). Narrative review of health-related quality of life and its predictors among patients with coronary heart disease. International Journal of Nursing Practice, 22, 4-14.

20. Moher, D., Liberati, A., Tetzlaff, J., Altman, D. G., \& PRISMA Group (2009). Preferred reporting items for systematic reviews and meta-analyses: The PRISMA statement. BMJ, 339, b2535.

21. Cohen, J. (1988). Statistical power analysis for the behavioral sciences (2nd edn.). Hove: Lawrence Erlbaum Associates.

22. Downs, S. H., \& Black, N. (1998). The feasibility of creating a checklist for the assessment of the methodological quality both of randomized and non-randomized studies of health care interventions. J Epidemiol Community Health, 52(6), 377-384.

23. Hajduk, A. M., Kiefe, C. I., Person, S. D., Gore, J. G., \& Saczynski, J. S. (2013). Cognitive change in heart failure: A systematic review. Circulation Cardiovascular Quality and Outcomes, 6(4), 451-460.

24. Pimentel, C. B., Lapane, K. L., \& Briesacher, B. A. (2013). Medicare part $\mathrm{D}$ and long-term care: A systematic review of quantitative and qualitative evidence. Drugs and Aging, 30(9), 701-720.

25. Hosseini, S., Chaurasia, A., \& Oremus, M. (2017). The effect of religion and spirituality on cognitive function: A systematic review. The Gerontologist. https://doi.org/10.1093/geront/gnx02 4.

26. Agli, O., Bailly, N., \& Ferrand, C. (2015). Spirituality and religion in older adults with dementia: A systematic review. International Psychogeriatrics, 27, 715-725.

27. Park, C. L., Wortmann, J. H., \& Edmondson, D. (2011). Religious struggle as a predictor of subsequent mental and physical wellbeing in advanced heart failure patients. Journal of Behavioral Medicine, 34(6), 426-436.

28. Park, C. L., Lim, H., Newlon, M., Suresh, D. P., \& Bliss, D. E. (2014). Dimensions of religiousness and spirituality as predictors of well-being in advanced chronic heart failure patients. Journal of Religion and Health, 53(2), 579-590.

29. Sacco, S. J., Park, C. L., Suresh, D. P., \& Bliss, D. (2014). Living with heart failure: Psychosocial resources, meaning, gratitude and well-being. Heart and Lung, 43(3), 213-218.

30. Park, C. L., \& Sacco, S. J. (2017). Heart failure patients' desires for spiritual care, perceived constraints, and unmet spiritual needs: relations with well-being and health-related quality of life. Psychology, Health \& Medicine, 22(9), 1011-1020.

31. Trevino, K. M., \& McConnell, T. R. (2014). Religiosity and religious coping in patients with cardiovascular disease: Change over time and associations with illness adjustment. Journal of Religion and Health, 53(6), 1907-1917.

32. Trevino, K. M., \& McConnell, T. R. (2015). Religiosity and spirituality during cardiac rehabilitation: A longitudinal evaluation of patient-reported outcomes and exercise capacity. Journal of Cardiopulmonary Rehabilitation and Prevention, 35(4), 246-254.

33. Beery, T. A., Baas, L. S., Fowler, C., \& Allen, G. (2002). Spirituality in persons with heart failure. Journal of Holistic Nursing, 20(1), 5-25.

34. Westlake, C., Dracup, K., Creaser, J., et al. (2002). Correlates of health-related quality of life in patients with heart failure. Heart and Lung, 31(2), 85-93.

35. Blinderman, C. D., Homel, P., Billings, J. A., Portenoy, R. K., \& Tennstedt, S. L. (2008). Symptom distress and quality of life in patients with advanced congestive heart failure. Journal of Pain and Symptom Management, 35(6), 594-603.

36. Park, C. L., Malone, M. R., Suresh, D. P., Bliss, D., \& Rosen, R. I. (2008). Coping, meaning in life, and quality of life in congestive heart failure patients. Qual Life Res, 17(1), 21-26.

37. Bean, M. K., Gibson, D., Flattery, M., Duncan, A., \& Hess, M. (2009). Psychosocial factors, quality of life, and psychological distress: ethnic differences in patients with heart failure. Progress in Cardiovascular Nursing, 24(4), 131-140.

38. Bekelman, D. B., Parry, C., Curlin, F. A., Yamashita, T. E., Fairclough, D. L., \& Wamboldt, F. S. (2010). A comparison of two spirituality instruments and their relationship with depression and quality of life in chronic heart failure. Journal of Pain and Symptom Management, 39(3), 515-526.

39. Karademas, E. C. (2010). Illness cognitions as a pathway between religiousness and subjective health in chronic cardiac patients. Journal of Health Psychology, 15(2), 239-247.

40. Abolghasem-Gorji, H., Bathaei, S. A., Shakeri, K., Heidari, M., \& Asayesh, H. (2017). The effect of religiosity on quality of life in Muslim patients with heart failure: A study in Qom, the religious capital of Iran. Mental Health, Religion and Culture, 20, 217-228.

41. Bang, J. S., Jo, S., Kim, G. B., Kwon, B. S., Bae, E. J., Noh, C. I., \& Choi, J. Y. (2013). The mental health and quality of life of adult patients with congenital heart disease. International Journal of Cardiology, 170(1), 49-53.

42. Pargament, K. I., Ensing, D. S., Falgout, K., et al. (1990). God help me: I. Religious coping efforts as predictors of the outcomes to significant negative life events. American Journal of Community Psychology, 18(6), 793-824.

43. Peterman, A. H., Fitchett, G., Brady, M. J., et al. (2002). Measuring spiritual well-being in people with cancer: The functional assessment of chronic illness therapy-Spiritual Well-being Scale (FACIT-Sp). Annals of Behavioral Medicine, 24, 49-58.

44. Abeles, R., Ellison, C. G., George, L. K., et al. (1999). Multidimensional measurement of religiousness/spirituality for use in health research. Kalamazoo, MI: John E. Fetzer Institute.

45. Exline, J. J., Yali, A. M., \& Sanderson, W. C. (2000). Guilt, discord, and alienation: The role of religious strain in depression and suicidality. Journal of Clinical Psychology, 56, 1481-1496.

46. Ellison, C. W. (1983). Spiritual well-being conceptualization and measurement. Journal of Psychology Theology, 11, 330-340.

47. Reed, P. G. (1986). Religiousness among terminally ill adults and healthy adults. Research in Nursing \& Health, 9, 35-41.

48. Cella, D. (1997). Manual of the Functional Assessment of Chronic Illness Therapy (FACIT) measurement system, version 4. Evanston, IL: Center on Outcomes, Research and Education (CORE), Evanston Northwestern Healthcare and Northwestern University. 
49. Carver, C. S., Scheier, M. F., \& Weintraub, J. K. (1989). Assessing coping strategies: A theoretically based approach. Journal of Personality and Social Psychology, 56, 267-283.

50. Ironson, G., Solomon, G. F., Balbin, E. G., et al. (2002). The Ironson-woods Spirituality/Religiousness Index is associated with long survival, health behaviors, less distress, and low cortisol in people with HIV/AIDS. Annals of Behavioral Medicine, 24(1), 34-48.

51. Allport, G. W., \& Ross, J. M. (1967). Personal religious orientation and prejudice. Journal of Personality and Social Psychology, $5,432-443$.

52. Rohrbaugh, J., \& Jessor, R. (1975). Religiosity in youth: A personal control against deviant behavior. Journal of Personality, 43(1), 136-155.

53. Silber, T. J., \& Reilly, M. (1985). Spiritual and religious concerns of the hospitalized adolescent. Adolescence, 20, 217-224.

54. Campbell, A., Converse, P. E., \& Rodgers, W. L. (1976). The quality of American life: Perceptions, evaluations, and satisfactions. New York: Russell Sage.

55. What quality of life? The WHOQOL Group. (1996). World Health Organization quality of life assessment. World Health Forum, 17, 354-356.

56. Avis, N. E., Smith, K. W., Hambleton, R. K., Feldman, H. A., Selwyn, A., \& Jacobs, A. (1996). Development of the multidimensional index of life quality: A quality of life measure for cardiovascular disease. Med Care, 34(11), 1102-1120.

57. Ware, J. E., \& Sherbourne, C. D. (1992). The MOS 36-item shortform health survey (SF-36): A conceptual framework and item selection. Med Care, 30, 473-483.

58. Ware, J. E., Kosinski, M., \& Keller, S. D. (1996). SF-12: An even shorter health survey. Medical Outcomes Trust Bulletin, 4, 2.

59. RAND Health (2007) Medical outcomes study: 36-item short form. Retrieved November 11, 2017, from http://www.rand.org/ health/surveys_tools/mos/mos_core_36item.html.

60. Rector, T. S., \& Banks, A. J. (1996). Use of prognostic variables in the care of patients with chronic heart failure. Cardiology in Review, 4, 254-262.

61. Foster, C., Oldridge, N. B., Dion, W., Forsyth, G., Grevenow, P., Hansen, M., et al. (1995). Time course of recovery during cardiac rehabilitation. Journal of Cardiopulmonary Rehabilitation and Prevention, 15(3), 209-215.

62. Green, C. P., Porter, C. B., Bresnahan, D. R., \& Spertus, J. A. (2000). Development and evaluation of the Kansas City Cardiomyopathy Questionnaire: A new health status measure for heart failure. Journal of the American College of Cardiology, 35(5), $1245-1255$.

63. Oman, D., \& Thoresen, C. E. (2005). Do religion and spirituality influence health? In R. F. Paloutzian \& C. L. Park (Eds.), Handbook of the psychology of religion and spirituality (pp. 435-459). New York: Guilford.

64. Powell, L. H., Shahabi, L., \& Thoresen, C. E. (2003). Religion and spirituality. Linkages to physical health. American Psychologist, $58,36-52$.

65. Lucchese, F. A., \& Koenig, H. G. (2013). Religion, spirituality and cardiovascular disease: Research, clinical implications, and opportunities in Brazil. Revista Brasileira De Cirurgia Cardiovascular, 28, 103-128.

66. Zinnbauer, B. J., Pargament, K. I., \& Scott, A. B. (1999). The emerging meanings of religiousness and spirituality: Problems and prospects. Journal of Personality, 67(6), 889-919.

67. Dal Bello-Haas, V., Andrews-Hinders, D., Bocian, J., Mascha, E., Wheeler, T., \& Mitsumoto, H. (2000). Spiritual well-being of the individual with amyotrophic lateral sclerosis. Amyotroph Lateral Scler Other Motor Neuron Disord, 1, 337-341.

68. Galbreath, A., Krasuski, R., Smith, B., Stajduhar, K., Kwan, M., Ellis, R., et al. (2004). Long-term healthcare and cost outcomes of disease management in a large, randomized, community-based population with heart failure. Circulation, 110, 3518-3526.

69. Rector, T. S., Anand, I. S., \& Cohn, J. N. (2006). Relationships between clinical assessments and patients' perceptions of the effects of heart failure on their quality of life. Journal of Cardiac Failure, 12, 87-92.

70. Shea, B. J., Grimshaw, J. M., Wells, G. A., Boers, M., Andersson, N., Hamel, C., \& Bouter, L. M. (2007). Development of AMSTAR: A measurement tool to assess the methodological quality of systematic reviews. BMC Medical Research Methodology, 7, 10. https://doi.org/10.1186/1471-2288-7-10. 